\title{
Lenguaje y Metafísica
}

Si en alguna esfera de la experiencia, el arcano metafísico de la realidad se hace visible, en cierto modo, sin perder su carácter enigmático, es sin duda en el fenómeno del lenguaje. En el lenguaje, en efecto, podemos aislar tres cosas, a saber: un elemento sensible (audible), un sentido suprasensible al cual, por constittir una forma de existencia en la mente y por oponerse como entidad subsistente y en sí a la apariencia sensible, le llamamos elemento ontológico y por último, una relación entre ambos mediante la cual el fundamento ontológico se hace aprehensible a través de la palabra, del verbo. Si pensamos ahora en que, al fin y all cabo, el problema mietafísico poìe excelencias consiste en comprẻnder, en intuir la relación entre el ser como fundamento y sentido de la realidad y el aparecer como su expresión. tendremos que concluir que el lenguaje es, en verdad, un fenómeno representativo de la más profunda y misteriosa estructura de la existencia.

Este carácter, que llamaríamos ejemplar o representativo del lenguaje por relación al fenómeno del aparecer universal, puede acaso servirnos para inferir, más allá del mero esquematismo de ser y aparecer, mediante la experiencia psicológica de los planos de la apariencia y gracias al estudio del enlace entre sentido y expresión, algo sobre el tránsito del ser al aparecer. El movimiento que va del sentido a la expresión verbal es un movimiento centrífugo. La ex- 
presión supone un movimiento centrifugo que va desde una cierta idea o sentimiento del alma a la exterioridad sensible de la palabra. Es un movimiento centrifugo y evolutivo. La comprensión es un movimiento inverso, involutivo $y$ centrípeto, por el cual, más allá de la expresión se busca ei sentido originario, el fundamento interior, que nosotros llamamos ontológico de la palabra. Y la dificultad de describir esos movimientos consiste en que aunque contrarios, esos movimientos son complementarios y simultáneos. El hablante se interpreta a sí mismo, se entiende, se oye. El oyente se expresa, en cierta medida a sí mismo en las paliabras del hablante. Y así, la emanación del sentido de donde brota la palabra y el retorno al sentido que constituye la comprensión son por su naturaleza misma y por la profundidad y dificultad de las cuestiones que suscitan, comparables si no idénticos a los pasos metafísicos opuestos e inseparables que la intuición neoplatónica penetró tan profundamente y que no son otros que los de la implicación y la explicación genética de lo real.

Mediante la consideración de dos ejemplos nos pondremos en camino de descubrir fos tipos generales de enlace entre las significaciones y los signos y luego, junto con la base para una concepción de conjunto sobre la expresión en el lenguaje, la posibilidad de realizar algunas inferencias legítimas sobre el maravilloso fenómeno del aparecer universal.

Supongamos que nos proponemos aislar el sentido de la estrofa de Jorge Manrique que dice:

Nuestras vidas son los ríos

Que van a dar a la mar

Que es el morir 
Si dijéramos que el sentido de esta estrofa es que "nuestras vidas terminan con la muerte" cometeríamos un error, puesto que si Jorge Manrique hubiera querido decir ínicamente que nuestras vidas terminan en la muerte, lo habría expresado en esa forma, y no fué así, sino que el poeta pensó la vida y el "morir" bajo las especies de los ríos y del mar. Vió nuestras vidas como los ríos que van al mar, que es el morir. Sólo en esta forma pudo expresarse su sentimiento de la vida y de la muerte, y de tal modo que no podía cambiar ni quitar una palabra sin que quedase trunco $y$ en consecuencia inexpresado el sentido de la estrofa. De donde concluimos que el sentido no se adhiere exteriormente a la palabra ni se deposita en ella como el vino en la copa sino que la penetra e informa comunicándose a la totalidad de la expresión y componiendo con ella, por infusión, una sola e indivisible realidad. Se diría que sentido y expresión son dos ideas categoriales que se emplean, respectivamente, para indicar la unidad por relación a la variedad, lo invisible y sólo imaginable por relación a lo visible, lo permanente por relación a lo que puede cambiar. El sentido sería así la unidad, 16 invisible, fo pernanente, es decir aquello que tiene las calidades que ordinariamente se predican del ser. La expresión sería lo que está sujeto al cambio, lo que al fin y al cabo está incluso en el incontenible fluir de la vida. Y así, a la luz de este ejemplo, podríamos afirmar al propio tiempo la distinción lógica y la inseparabilidad de la expresión y del sentido.

Lo que hemos dicho a propósito de la estrofa de Jorge Manrique no basta empero, ni siquiera para el objeto de presentar con claridad al propio tiempo que la distinción esencial, el enlace entre el sentido y la expresión. Por- 
que hay un tipo de expresiones a las que no conviene la descripción que hemos intentado. Tomemos por ejemplo la fórmula $\mathrm{F}=$ ma. Aquí nos damos cuenta de que el sentido hubiese podido ser expresado en otra forma, con otras expresiones. Y que la fórmula, lejos de emanar directamente de un cierto movimiento del alma, implica una operación intelectual dirigida a esquematizar en términos de la más rigurosa simplicidad toda la posible variedad de la experiencia. Y de tal modo estos ejemplos nos hacen presumir que en el lenguaje se dan dos clases de operaciones, equivalentes a dos diversas actitudes intelèctuales o más propiamente anímicas: un acto emanatístico o hipostático, correspondiente de modo principal a la expresión poética y en el cual se difunde la unidad primitiva del sentido en la varia multiplicidad de la apariencia, y un acto que llamaremos demiúrgico ( I ) y que reduce a la organización, al esquema, al sistema de formas conceptuales, la incoherente, la caótica e inmediata multiplicidad de las apariencias. Operaciones que acaso corresponden a los dos géneros de energía que Klages descubre en la actividad de la palabra: la simbólica, indicativa de naturalezal cinétida fola delinitante, conceptual de naturaleza potencial. (2).

Ocupémonos primeramente de la que llamamos operación demiúrgica, reservando para más adelante el estudio de la operación hipostática a la que, por otra parte concederemos mayor importancia y signifticación metafísicas.

(1) L. Estève, en un estudio intitulado: Autour de Valéry (Reviue de Métaphysique et de Morale, Janvier-Mars, 1928) alude a la función demiúrgica del lenguaje, pero en un sentido que no coincide con el que aqui damos a la misma expresión.

(2) Der Geist als widersacher der Seele I Band, Leipzig 1929, página 434. 
La operación demiúrgica, a la que calificamos de este modo recordando al dios platónico que convirtió el caos en cosmos, guiado por la visión de las ideas, realiza una función abstractiva y de estabilización en el dominio heterogéneo y cambiante de la experiencia inmediata. En la multiplicidad cualitativa y variable que llena así el mundo de las imágenes objetivas como el mundo interior de nuestra sensibilidad, la palabra establece ciertas formas comunes, ciertas denominaciones generales que al propio tiempo que sirven a la sistematización teorética, son instrumentos de acción, formas designativas de comunicación y universal inteligibilidad. Los nombres que convienen a una multiplicidad de imágnes o de estados afectivos internos, borran lo que cada una de esas imágenes o estados tiene de irreductible y único para no retener sino sus caracteres comunes; por otra parte en el incesante, irreversible fluir de la vida interior, el lenguaje fija para siempre, en la forma relativamente invariable del nombre, ciertos modos de ser del alma y les confiere una falaz solidez. $Y$ así puede decir Bergson, en sentencial inatacable desde sur punto de vista: "Luego la palabrāodecentoriosllbien Idefinidos, la palabra brutal, que almacena lo que hay de estable, de común y por consiguiente de impersonal en las impresiones de la humanidad, aplasta o por lo menos recubre las impresiones delicadas y fugitivas de nuestra conciencia individual. Para luchar con armas iguales, éstas deberían expresarse por paTabras precisas; pero estas palabras, apenas formadas, se volverían contra la sensación que les dió nacimiento, e inventadas para certificar que la sensación es inestable, le inpondrían st propia estabilidad." (3) página 100 .

(3) Essai sur les Données Immédiates de la Conscience París 1912, 
Esta función clasificatoria y estabilizadora del lensuaje obedece, ora a una necesidad pragmática de carácter eminentemente social, ora a una intención teorética. La necesidad de comunicación interindividual impone sin duda una cierta despersonalización del contenido anímico que se comunica y requiere la creación de signos capaces de circular como la moneda. La intención teorética persigue, en primer término un ideal de claridad y distinción y por eso introducè en la materia más o menos confusa y caótica de las apariencias separaciones y agrupamientos susceptibles de denominaciones simples, y en segundo término, la intención teorética, al buscar los fundamentos o las esencias efectúa un trabajo de reducción que elimina las particularidades accidentales para retener únicamente lo sustancial, que designa con un nombre. Hay filósofos para quienes, genéticamente, la actitud pragmática es anterior a la actitud especulativa, y según los cuales los conceptos (y en consecuencia los términos que los expresan) se đarían primitivamente más como direcciones para la actividad práctica que como referencias a la estructura ontológica de lo real. Sea fo que fuere, la actitud demiúrgica al propiortiempo quivelordenave inmoviliza; y en cualquiera de sus dos direcciones, pragmática o especulativa, es siempre programática, impersonal y hostil a la variedad concreta y a la movilidad creadora de la vida.

La tendencia del lenguaje, en este aspecto de su activiđad, es al esquematismo más extremado y a la economía más rigurosa en la expresión, todo lo cual conduce a la instauración de un absoluto convencionalismo en la adopción y en el manejo de los signos. Basta pensar en el lenguaje matemático para darse cuenta así de la tendencia como de los resultados de este tipo de actividad en el lenguaje. Y si se quiere mayor ilustración, piénsese en algunas fórmulas lógicas co- 
mo, por ejemplo, en las famosas combinaciones verbales Bárbara, Celarent, Darii, Ferio etc. Hasta en la disciplina del derecho se tiende a una especie de figuración algebraica de las relaciones jurídicas. Ejemplo: $\mathrm{H}_{\mathrm{I}}+\mathrm{H}_{2} \ldots \mathrm{AO}_{2} \mathrm{~S}$ es, según Schreier, la fórmula de la dación en pago. (4)

El esquematismo y la economía que caracterizan este tipo de actividad lingüística han originado la tendencia moderna a formar palabras que condensan una frase o una serie de nombres mediante la unión de sus iniciales, resultando a veces horribles combinaciones que generalmente adquieren circulación internacional y que así revelan la tendencia cosmopolita del lenguaje conceptual, al que acaso con cierta impropiedad pero justificadamente en el fondo hemos llamado demiúrgico. Ejemplo: SIPA, COSACH, FIFA. Es la paradójica orgía del esquema y del convencionalismo, o, si se prefiere, la tiranía del signo bajo cuyo imperio la realidad concreta de las cosas y de llas imágenes se disipa y se picrde.

Lo cual no atañe empero ni a la importancia intrínseca del lenguajes conceptual ni a sti significación en el ámbito de la gnoseología y de la lógica. En efecto el lenguaje, ejercitándose en la dirección conceptual no sólo delimita, fija y por decirlo así, acuña los signos transmisibles del pensamiento, sino que gracias a sus leyes morfológicas y a las que rigen las relaciones entre el sentido y la expresión, pone en transparencia, dibuja, hace sensible la estructura, el esqueleto formal de la inteligencia, y revela, además, las posibilidades de referencia intencional entre el pensamiento y los objetos.

Las profundas investigaciones de Husserl sobre la sig-

(4) Frifz Sehreier, Concepto y Formas Fundamentales del Derecho, Traducción Castellana, Buenos Aires 1942, página 12. 
nificación y sobre las leyes a priori que rigen el enlace de las significacones cuando se organizan en una unidad de sentido se refieren al tipo de actividad lingüística que denominamos demiúrgica y que conviene al aspecto meramente intelectual, lógico y abstractivo del espíritu.

Las significaciones, en su enlace, obedecen a leyes derivadas de la propia esencia del significar y que, con prescinclencia de la materia significada, se fundan en la forma o sea en el papel, en la categoría gramatical de la significación. De donde se deriva según Husserl "el gran problema igualmente fundamental para la lógica y para la gramática de establecer esta constitución a priori que envuelve el reino de las" significaciones y de investigar, "en una morfología de las significaciones" el sistema a priori de las estructuras formales, esto es de las estructuras que prescinden de toda particularidad material de la significación". (5)

En este empeño llega Husserl a la concepción de una lógica-gramática pura que establecería algo así como el "esquema ideal" del lenguaje y sería el común fundamento esencial y no empírico deotodas las lenguas. Sintesis a priori, morfología de (las figuras, nolaccidentales ni locales sino esenciales y necesarias del enlace de las significaciones en unidad de sentido.

En el curso de sus admirables desarrollos Husserl dice lo siguiente que, por su proyección extralógica, interesa de modo especial al objeto de nuestro estudio: "La esfera de la significación es mucho más amplia que la de la intuición, esto es, que la esfera total de los cumplimientos posibles", (6) es decir, aclaramos nosotros, que la esfera de los

(5) Investigaciones Irógicas, Traducción Castellana, Madrid 1929, Tomo 3, página 104.

(6) Ibidem, Tomo 4, página 148. 
correlatos objetivos, reales de la significaciones. Prolongando este pensamiento a la esfera ontológica diríamos que es como si la apariencia se desprendiese del ser de los objetos y se constituyese en un mundo vacío, en un mundo de ilaciones falaces cuyos miembros aluden sin duda a los objetos de la intuición pero que, en su conjunto, forman complejos sin senticlo unitario, algo menos que absurdos pero que se dan dentro de las normas de la legalidad sintáctica. A este conjunto de formas desprovistas de sentido unitario creemos que le corresponde propiamente la categoría de irrealidad y no, como suele sostenerse, contrariando el profundo sentido de la tradición platónica, al mundo de los objetos ideales. (7)

En resumen el lenguaje, en cuanto instrumento de conceptualización, desempeña en la economia del mundo anímico el mismo papel que representan en el torrente del devenir universal, las fuerzas de estabilización, que instituyen ciertas constancias, ciertas uniformidades. Y como sintaxis, el lenguaje es sin duda una manifestación particular del imperio universal de la forma, es decir de todas las posibilidades de la energía a configurarse y a organizarse según modos de coherencia y"de infeligibilidad. Portéedo po cual, acaso, Platón en el Cratilo, atribuia al legislador la obra de nombrar los objetos con nombres que al propio tiempo que expresasen (imitasen) su esencia, indicasen su función en el sistema de relaciones que constituyen el mundo y la vida.

(7) Nosotros no aceptamos la división dicotómica de lo existente en real e ideal, que excluye la realidad de lo ideal, porque pensamos que lo ideal es real y que la realidad de los objetos espaciotemporales se integra con elementos de idealidad. Todos los objetos existentes son reales ya sean físicos o psíquicos, ya sean ideales, y por eso lo irreal es una categoría que no concierne a los objetos mismos sino a la relación entre el signo y el objeto; y así llamamos irreal a lo sin sentido, a lo que no tiene posibilidad de cumplimiento, a lo que no existe ni puede existir. 
Llamamos operación hipostática aquella en que el sentido, en sí mismo invisible, suprasensible desciende a encarnarse y configurarse en la palabra. Y la llamamos así por analogía con el paso metafísico que los neoplatónicos denominaban emanación hipostática y en el cual el Uno, sin dejar de ser uno, se transladaba a la alteridad intelectual, y la inteligencia universal se comunicaba y transfundía en el alma. Así el senticlo se realiza a través de los distintos planos de la expresión y, sin dejar de ser lo que es, se configura y aparece. Con esto quizá reanudamos una antiquísima tradición, ya que algunos viejos cosmólogos, para aludir a la inteligencia que ordena, gobierna y configura el universo, hablaban de la sintaxis cósmica, expresando así con una sola palabra la estructura sintética y la calidad expresiva de la actividad universal.

Pero quizá esta analogía puede ser desarrollada con beneficio para la comprensión del gran misterio del lenguaje. La serie de hipóstasis o de emanaciones hipostáticas que van del Uno a la inteligencia y de éstâtalâma la cual a su vez configura Jerinformai el lhundo material, se intègra con un movimiento inverso que vuelve por la vía de la negación y de la eminencia al ser y al Uno.Procesión y retorno se llaman respectivamente estos movimientos y son comparables a los movimientos de expresión y captación de sentido en el lenguaje. Pero hay algo más, porque la procesión y el retorno cósmicos que no son movimientos separados sino complementarios aunque opuestos, nos dan la concepción metafísica en que mejor se expresa, sin duda, la relación de implicación y oposición de la aparición y del sentido.

Estudiando ésta que llamamos operación hipostática, vemos que el lenguaje no tiene por única función la de trans- 
mitir o entender órdenes, o la de clasificar los objetos, o la de dirigir como un semáforo el tránsito en medio de la confusa movilidad de la vida. Parece, por el contrario, que el lenguaje tiene además la función de manifestar sin intención ordinatoria ni utilitaria, el contenido interior del alma. Manifestar, es decir revelar el contenido implícito de la vida no sólo a los demás sino a los propios ojos de la propia conciencia, como un destello, o una fulguración o un reflejo particular del ferómeno universal del aparecer.

Tratemos ahora, de aproximarnos al proceso en que este contenido interno que es el sentido, se configura y expresa en la palabra.

Conocemos pocos intentos verdaderamente profundos de descripción del tránsito del sentido a la imagen y de la imagen a la palabra. Acaso porque esa descripción es por todo extremo difícil y tal vez imposible ya que estas categorías: sentido, imagen, palabra, más que momentos históricos, etapas separadas de la procesión expresiva son momentos ideales, aspectos de una realidad indivisibile. El sentido es a la vez anterior y final. Precede y preside, las frases de la evolución expresiva y también las corona, porque aparece como un resultado, como un brote suprasensible de la expresión acabada. $Y$ es inmanente y trascendente. Es inmanente, interno y hasta consustancial a todos los elementos de la frase o del discurso. Pero los trasciende, y por encima de ellos existe y subsiste en si aunque no sea posible definirlo. Como el ser que no se agota ni disuelve en la infinita variedad de las apariencias, pero que no podemos aprehender ni definir en la pura, absoluta desnudez de su esencia.

Para hablar en lenguaje aristotélico diremos que hay una forma final que precede, preside, orienta y al fin se en- 
carna en el movimiento configurativo de la mente, del mismo modo que la forma. final de la flor y del fruto preside las fases del devenir biológico de la planta. No debemos olvidar sin embargo una cosa a saber: Que el movimiento configurador del lenguaje es creador en el sentido de que la expresión no sólo manifiesta y traduce, sino que también suscita y produce. La forma y el acto preexisten en cierta medida pero algo nuevo e imprevisible surge luego en cours de routc. Sin que nada, empero, rompa la fitulación del todo por respecto a la primitiva entidad de sentido.

Las finas y profundas observaciones de Bergson en "L'Intuition Philosophique" sobre la simplicidad de las intuiciones primordiales de los grandes filósofos y la complicación más o menos considerable del aparato verbal, configurativo y técnico en que esa intuición simple se traduce, perdiéndose a veces y reencontrándose otras en el zigzag de la exposición, nos ilustran sobre la tensión entre la intención de sentido y la expresión, y la doctrina bergsoniana del esquema dinámico, aristotélica en el fondo, nos instruye sobre el proceso evolutivo del contenido psíquico que tiende a exteriorizarse mediante li palabrạscel tránsito del sentido a la expresión aparece en estos estudios como algo comparable a la proyección luminosa en la cual, a partir de un foco donde existen las figuras de la aparición como meras virtualidades, se expande y difunde el sentido encarnándose en formas cada vez más definidas hasta llegar al plano final en que, como en la pantalla de los cinematógrafos, adquieren realidad y aparecen las figuras implicadas en la intención originaria.

En esta primera aproximación nos hemos ocupado del lenguaje, principalmente, como expresión del contenido representativo de la mente: ideas, imágenes y sus relaciones. 
No hemos considerado el lenguaje como signo expresivo de la emoción. No sólo de aquellas emociones que se acom.pañan de signos somáticos, como el miedo o la cólera, sino 'ie aquellas otras más vagas, acaso más profundas, más sutiles y delicadas, que parecen rebeldes a toda definición y en consectrencia a toda expresión. No nos hemos ocupado de la poesía que es por excelencia el órgano expresivo de la emoción, ya que en ella se manifiestan los más sutiles, los más subjetivos, los más delicados matices de la vida afectiva; se manifiestan y propagan como si el configurarse no fuera únicamente un acto destinado a la comprensión y captación del sentido por el oyente, sino un medio de transmisión y de contagio destinado a hacer que el oyente no sólo comprenda sino que participe en una cierta oncla, en una cierta corriente o marea de la vida del alma.

$Y$ he aquí como esta propiedad del henguaje-como vehículo y expresión de la vida afectiva-nos conduce a formular algunas muy breves consideraciones sobre la fantasía poética, entendida como la actividad del alma encaminada, pos modg principal, a configurar, transmitir y continuar la corriente emocional de la vida.

Si un hombre presa de la cólera dice: "siento uma in-. tensa cólera" o si un noválista escribe "Juan tuvo miedo", todo el mundo capta de inmediato eli sentido de estas frases, pero es evidente que si se prescinde del gesto o del acento de significación en un caso y del contexto en el otro estas frases contienen una significación meramente abstracta. Indican que los sujetos de ambas oraciones experimentan una cierta emoción, cuya esencia universal es definible conceptualmente y, por lo tanto, la misma para todos los seres humanos. Ni expresan la cólera concreta de $\mathrm{X}$ ni el miedo intransferible de Juan, y ađemás no nos per- 
miten participar emocionalmente en estos estados aními$\cos$ ni con la participación real que Scheler llamaría Einsfïhlung, ni con la participación estética que Lipps llamaría Einfïhlung.

¿Qué condiciones debe llenar pues la expresión para ser realmente la expresión de un sentimiento, de una emoción del alma, y para suscitar, junto con la participación afectiva, el misterioso encanto de la poesía que no es al fin y al cabo sino el encanto de la expresión lograda o más exactamente de la expresión que a través de la magia de su color o de su música, nos entrega vivo y palpitante el sentido?

Nos parece que estas condiciones son de tres clases: imaginativas, sintácticas y fonéticas.

Parece ser que la primera condición de la poesía consiste en que el sentimiento se encarne en imágenes. Lo cual no significa que la imagen sea un signo indirecto de la emoción sino al contrario, que comparable al gesto expresivo, sea su cuerpo visible, de tal modo que el sentimiento expresado y la imagen expresiva aparezcan como la única apariencia posible de la emocion manifestada. Las imágenes, y en general las formas expresivas, pueden expresar el sentimiento de dos maneras: o bien la imagen es una hipóstasis directa, inmediata, del sentimiento, o bien es algo así como la proyección cinética de la emoción. Ejemplo del primer caso pueden ser los versos tan conocidos de Verlaine:

Il pleure dans mon coeur

Comme il pleut sur la ville

O los versos de Conrad Ferdinand Meyer:

Tag meines Lebens!

Gen Abend geht's.... 
Para aclarar lo que acabamos de decir cuando hablamos de proyección cinética del sentimiento como forma expresiva de la emoción, pensemos en el "no" que proferimos ante una noticia desagradable. Este es un no que no niega la existencia del suceso ingrato sino que lo rechaza. Otro ejemplo: el famoso soneto atribuido a Santa Teresa de Avila expresa el amor como causa y a la vez como efecto de los movimientos del alma suscitados por la visión del sacrificio y de la muerte de Jesús.

Considerando ahora el aspecto meramente verbai de la. expresión afectiva se presentan a nuestra atención dos aspectos del lenguaje que se conjugan, convergen y conspiran a la eficacia de la manifestación comunicativa del sentimiento, a saber: ell aspecto sintáctico y el aspecto fonético de la expresión.

En cuato al aspecto sintáctico, gramáticos y linguistas asientan en primer término que en el lenguaje afectivo se perturba o desaparece el orden lógico, la estructura estrictamente gramatical de laj expresión os de la frase. Es el anacoluto, desorden aparente; es la interrupción, repercusión cinética de la violencia interna. Según Vendryes mientras en la lengua escrita-que se supone no afectiva-el orden es de subordinación, en la hablada-afectiva-es de yuxtaposición. De yuxtaposición en las cláusulas, con acentuación en los movimientos dominantes y atenuación $u$ oscurecimiento de las relaciones meramente conceptuales o lógicas. Los lingüistas señalan la reduplicación o repetición de las palabras como medio de acentuar la ascensión de la onda afectiva. Repetición, reiteración en que se anuncia ya el gran fenómeno universal y poético del ritmo. En fin, hablan ( $\mathrm{Ba}-$ 1ly) de los juegos, transposiciones y figuras gramaticales en 
que se transparenta la actividad a la vez intelectual e ilógica del lenguaje afectivo.

Hay una evidente relación de continuidad vital entre el sonido de la palabra y el fondo emocional o la imagen cargada de afectividad que ella expresa. Una relación misteriosa en la cual influye sin duda, en cierta medida, el hecho de que el hábito establezca una cierta asociación automática entre un determinado 'sonido y una significación más o menos precisa; pero en la que hay algo más: una indefinible acción mágica de la palabra sobre el alma, acción a cuyo influjo se suscita en el oyente un movimiento afín o idéntico al movimiento verbal que hiere las cuerdas de su sensibilidad "Como el sonido de unta lira, diría Plotino, que hace vibrar simpáticamente otra dira". Por lo cual afirmamos que existe una eficacia del sonido verbal que no se reduce ni a la asociación habitual entre el signo y la cosa ni tampoco al efecto de las llamadas asociaciones ideofónicas, o sea a la analogía acústica entre la palabra y las características físicas del objeto representado Debiendo tenerse en cuenta a este respecto que la llamada armonía imitativa $u$ onomatopeya reproduce, según la observación de Klages, más bien ruidos que sonidos propiamente dichos. Observación que podemos comprobar con los siguientes ejemplbs castellanos: silbido, chasquido, murmurio, repique, chispa etc.

La eficacia del sonido como vehículo y suscitador de emoción es mucho más sutil e indefinible. Deriva de alguna relación inexplorada entre la vibración física y el alma, relación en que a ciertos sonidos corresponden ciertas actitudes o estados anímicos, independientemente de la semejanza entre el sonido verbal y el sonido natural que representa. Se 
diría que existe una armonía preestablecida entre la melodía de las palabras y la oscilación de la vida interior.

Tomándolo de un viejo libro de literatura y modificándolo al influjo de observaciones personales, presentamos el siguiente esquema de correlación anímico-fonética de las vocales:

La A expresa y suscita sentimientos de calma, de plenitud, de elevación y también de extático transporte ante lo st1blime: casa, alma, ala, palabra, etc.

$\mathrm{La} \mathrm{O}$ es una vocal que tiene un cierto aliento cósmico. Es la vocal del Todo, y en la melodía de las palabras suscita una sensación de abundancia, de grandeza, de inmensidad: sol, todo, globo, colmo, cosnos etc.

La E es vocal estética y leve, esencialmente eufónica di. cen los gramáticos. Comunica su dulzura a los nombres femeninos en que abunda: Elena, Ester etc.

La I es vocal aguda, dinámica; expresa impulso, exceso con una tendencia a lo agudo y estridente como grito, chillido, o ilimitada posibilidad como infinito y también sutileza, delicada pequeñez como en hilo y cierta precisión cortante como en incidentesencidir, incisivo etc.

$\mathrm{La} U$ es vocal oscura y profunda. Viene del misterioso abismo metafísico. Es ontológica y mística: profundo, tumba, túmulo, duda. Y por ser abismática y profunda, es humilde con la fecunda humildad del humus que es la tierra vegetal, la eterna y maternal posibilidad de la vida. Si quisiéramos fantasear un poco diríamos que la $U$ es órfica, porque en la hondura de su sonido parece que se reunieran los extremos polares de la vida y de la muerte: la cuna y la tumba. Es interesante igualmente recordar a propósito de la $U$ las palabras alemanas de tan hondo sentido: Ur, Grund y Ursprung. 
Según Hermann Wirth (8) en el cosmos y en el hombre la vocal A nacería del asombro ante el advenimiento primaveral; en el verano, saludando el apogeo de la luz estival, surgirían apasionadamente la $\mathrm{E}$ y la $\mathrm{I}$, en el otoño la $\mathrm{O}$ y en el invierno la $U$ con que el hombre y el mundo se reintegran al seno de lo oscuro y profundo. $Y$ de esta suerte a la luz de estos ejemplos podría quizá afirmarse que en el mero sonido, en los simples fonemas como tales existiría una cierta alusión al fondo metafísico de las cosas y al esplendor del aparecer. Y así finalmente se diría que el sonido de la expresión hablada constituye la primera zona de confluencia o de interpenetración entre las potencias de la naturaleza y la conmoción interior del alma.

$Y$ aqui, hagamos un alto que nos permita una visión de conjunto en el trabajo de la fantasía poética, que estamos tomando como una experiencia ejemplar y diríamos metodológica para llegar a la comprensión metafísica.

Hay en el trabajo de la fantasía poética instantes que podríamos llamar de conxocación de las palabras. El poeta solicita la patabra que debe encarnar una cierta intención de forma, y la palabra predestinada acude, emerge desde el fondo ignorado de la subconciencia individual o desde el oscuro acervo universal de las formas. Entonces el poeta la reconoce, cual si por un efecto de reminiscencia recordara haberla encontrado en uri cierto pasado metafísico donde contempló su propia obra en toda su plenitud y perfección. Y sólo entonces, es decir, sólo cuando suena la palabra expresiva en el espacio poético, conoce el artista su verdadera emoción, su verdadera intención de forma, como si ella naciera

(8) Citado por Otto Hartmann en su libro Erde und Kosmos, Frankfurt am Main, 1938, página 201-202. 
con el cuerpo que le da la palabra. Las posibilidades ignoradas de la vida interior podrían compararse a las almas de que habla Plotino en las Enéadas y que sólo se encarnan en los cuerpos que por su forma responden a su aspiración más esencia1. Y así podríamos decir, utilizando las palabras de Bergson, quien emplea este símil neoplatónico para explicar la actualización de los recuerdos: "Que los cuerpos se elevan hacia las almas que les comunicarían la vida completa, y el alma mirando el cuerpo en que cree ver el reflejo de sí misma, se deja atraer, se inclina y cae". (9) Y de esta suerte por último, nos parece que podemos aproximarnos a la conprensión de este fenómeno diciendo que hay una cierta preexistencia de la forma final y perfecta en el trabajo, lleno a veces de vehemente ansiedad, con que el poeta busca la expresión.

Asi el lenguaje por su poder, por su capacidad de expresión, de evocación, de conmoción interior del alma nos ilustra sobre la heterogeneidad concreta y la totalidad orgánica y creadora de lo real. La palabra es un sonido, una vibración física, perón ella se contiene y 10 que es más, en ella aparece un sentide, iriteductible an la simple materialidad te la expresión aunque unido a ella por modo indisoluble. De esta suerte, para hablar en lenguaje pascaliano, diríamos que el lenguaje es una forma de la extensión en que se diversifica y expresa la unidad del pensamiento. $\mathrm{Y}$ aun más, diríamos que ambos aspiran al orden de la gracia en que tanto el sonido como el sentido se elevan sobre la pura materia y el mero pensamiento, a la emoción, a la intuición, a la erótica contemplación de lo absoluto y divino.

(9) Henri Bergson L'Energie Spirituelle. París, 1920 página 103. 
Pero hay una función eminente, a la vez de la fantasía y del lenguaje, que interesa por igual a la ontología y a la estética. $Y$ es la función metafórica que nosotros consideramos comprendida en la que llamamos revelación hipostática en el fenómeno de la expresión.

Se suele creer que se explica el proceso de formación de la metáfora considerándola como el resultado de una mera asociación por semejanza. Pero esa es una explicación insuficiente. Porque la semejanza, tomada en abstracto, es una calidad que puede relacionar las imágenes o las 'apariencias cualesquiera que sean, según los innumerables puntos de vista desde los cuales son susceptibles de ser contempladas o comparadas. La semejanza, como mera calidad formal, no constituye pues una verdadera ley, y así lo ha demostrado de una manera concluyente Bergson en "Materia y Memoria". Entre las apariencias que se juntan en la metáfora hay sin duda semejanza, pero hay algo más. Entre el sentido propio de la expresión metafórica y su sentido figurado hay un vínculo anímico más profundo un cierto vínculo emocional, el sentimiento de que la metáfora es verdaderamente la expresión y no la simple mâscara de un contenido natural o interno.

No intentamos ofrecer una teoría completa sobre la metáfora-en cuyo problema van envueltas las difíciles cuestiones relativas al origen y a la significación del mito y del arte. Nos limitaremos a decir, en síntesis, que la metáfora aparece a la vez, como la forma natural de expresión del sentimiento y como la zona o el punto de convergencia entre el yo y el no yo, el espíritu y la materia, la naturaleza y el alma.

No haremos tampoco ni la exposición ni la crítica detallada de las numerosas teorías sobre la metáfora, la ma- 
yor parte derivadas de la concepción psicoanalítica o de doctrinas afines a ella, y que, por lo general, consideran la nietáfora como una emanación de la subconsciencia, como una figura en que, por virtud del principio de ambivalencia, a la vez se descubre y encubre, se realiza y elude, el deseo escondido, la tendencia instintiva y oculta.

Lo que nos parece válido en todas estas teorías es que consideran la metáfora como una corporificación de tendencias profundas del alma que en la imagen metafórica, a la vez que se expresan, en cierto modo se disimulan y encubren. Lo que es discutible es el empeño de algunas escuelas por establecer conclusiones que podríamos llamar mecánicas, nomenclaturas de símbolos con sus correspondientes significaciones, como si la actividad metafórica o de simbolización, se ejercitase según leyes rígidas, como si fuera posible reducir abstractivamente a esquemas los innumerables e imponderables elementos humanos y cósmicos que se integran en la producción de la imagen simbólica: la metáfora.

Llamandolenguaje afectivo al lenguaje que sirve de expresión a los contenidos animicos en que predominan la sensibilidad "o la emoción sobre el esquematismo abstractivo o lógico, puede afirmarse en forma general, que el lenguaje afectivo es metafórico, es decir que los contenidos anímicos de esa calidad tienden siempre a ser configurados mediante imágenes tomadas del mundo sensible, o también que las imágenes sensibles, directamente captadas por los sentidos se expresan con palabras que aluden o se refieren a los sentimientos del alma. La metáfora expresa el alma con formas materiales y la materia con las formas del alma. Por lo cual la metáfora crea una zona de existencia en que el mundo interior y el externo se transfiguran por un como 
efecto de endósmosis o, para emplear el lenguaje de Jaspers, en que el uno se inflama en el otro.

La metáfora constituye una zona de identificación o interpenetración entre la naturaleza y el alma. En ella las formas visibles y tangibles de la materia aparecen como la expresión de un sentido espiritual, y algo más, como algo que al mismo tiempo retiene y exhala el alma. Materialización del alma y espiritualización de la materia. Doble y opuesta virtualidad de la imagen que al propio tiempo encubre y revela el enigma del hombre y del mundo, y en que la metáfora como forma universal de la fantasía y del mundo simboliza, según lo ha visto con profunda intuición $\mathrm{H}$. Pongs, la ambivalencia de la existenca, en que la estructura antinómica del mundo objetivo y la estructura antinómica del mundo subjetivo, de los sentimientos, se corresponden e integran. (I0)

Como encarnación de lo subconsciente y expresión de la vida afectiva, como contenido prelógico, mítico de la vida anímica, la metáforácpertenece al $]$ mundo del sueño- tomando esta palabra “sueño"cen su generalidad más significativa, como una proyección de la vida del alma, más allá del mero esquematismo intelectual o práctico. $\mathrm{Y}$ en este sentido es interesante revisar, aunque sea en forma muy, sumaria, las explicaciones e interpretaciones sọbre las imágenes del sueño que son, por esencia, imágenes metafóricas. Las escuelas psicoanalíticas, principalmente las que siguen la dirección freudiana interpretan los sueños, o mejor las imágenes del sueño, como expresiones indirectas en que a la vez se disimulan y se realizan los instintos. Hay empero

(10) L' Image Poétique et I' Inconscient en Psychologie du Langage por H. Delacroix y otros autores. París 1933, página 133. 
otra actitud, $\mathbf{u}$ otra dirección de las tendencias innatas, actitud que algunos psicólogos llaman anagógica, del griego anagein y que no se encubre como los instintos reprimidos, sino que más bien se ejerce como una actividad de orientación, de crítica y de elevación ideal, opuesta a la mera proyección instintiva.

Enunciando al propio tiempo el alcance cósmico de la metáfora y su sentido de elevación espiritual escribe Pongs: "Es ahí, en la esfera imaginada de los grandes fenómenos cósmicos, donde se justifica esta perspectiva por la cual todo poeta auténtico vuelve a encontrar en el Universo y en el yo, una misma y grande unidad divina. Las imágenes que se ofrecen a él vienen del fondo mismo de las cosas y son capaces de expresar los rasgos principales de su concepción del Universo. (II)

La actitud anagógica puede colaborar antinómicamente con la proyección instintiva. Al sueño meramente instintivo de alcance y significación subjetiva, se antepone el sueño anagógico, y por su unificación resulta el sueño integral de los grandes poetas, cuyas imágenes expresan no sólo la personalidad subjetiva def poeta sino su concepción cósmica $y$, lo que es más su relación primitiva con la vida cósmica. (Hölderlin, Goethe). En el sueño anagógico las imágenes no huyen, no se evaden, no contienen reticencias, sino que aceptan y exaltan la realidad oculta de las cosas. No mienten, anuncian. Y así dice Pongs a propósito de Hölderlin estas palabras aplicables a todo gran poeta: "El poeta viene a ser un mediador cuyas imágenes reflejan lo divino, velándolo, así como en el culto religioso lo divino se refleja y se comunica en el sacramento. En la creación imaginativa del poeta, lo

(11) Ibidem, página 157. 
verdadero revelado viene a ser lo verdadero comunicable". (12)

La unidad significativa de la metáfora poética constituye su transrealidad, que no es irrealidad sino proyección (anagógica) de la visión y de la imagen a una nueva dimensión de lo real.

Y he aquí que la poesía plantea y a la vez resuelve la gran cuestión de saber por qué en el mismo movimiento en que se expresa la emoción y en que se exhala el fondo subjetivo, musical diría Schiller, del alma parece también manifestarse, en el sonido de la palabra y en la materialidad más sutil de la imagen el sentido inmaterial de la naturaleza y de la vida. Es cono si el lirismo trascendiese de sí mismo y, elevándose sobre la mera confidencia sentimental y efímera, asumiera el carácter de verdadero lenguaje del ser, lenguaje que, brotado del fondo metafísico de las cosas está destinado a propagar en el espacio y en el tiempo el esplendor y el amor del sentido.

\section{Biblioteca de Letras \\ "Jorge Puccinelli Converso"}

Pero todavía no podemos terminar este ensayo.

En todo lo anterior hemos considerado el lenguaje $\mathrm{x}$ más especialmente la palabra - ora al estudiar la operación demiúrgica, en que el lenguaje ordena el mundo sensible para su interpretación teórica o para su utilización práctica, ora al describir la que llamamos emanación hipostáticacomo la manifestación de un sentido preexistente, como el resultado de un movimiento centrífugo, en suma como algo

(12) Ibidem, página 161. 
en que venía a expirar la onda expresiva y comunicativa del alma.

Lo hemos aludido sin duda, pero no hemos estudiado $\mathrm{ex}-$ plícitamente otro modo de actuación del lenguaje, acaso decisivo para la evolución espiritual del hombre. Es la función creadora o más exactamente formativa y constructiva del lenguaje, operación que siguiendo la dirección impresa por Humboldt a las investigaciones lingüísticas, ha estudiado Ernst Cassirer con singular penetración.

Según Cassirer el lenguaje no es un simple resultado, un mero producto sin acción propia en el contenido o en la actividad de la conciencia. Así como la representación objetiva, no es una simple copia de la realidad externa sino que ella se debe en gran parte al ejercicio de la función sintética de la mente, así las palabras son actos de la mente que al propio tiempo recogen, configuran y crean el contenido de la experiencia interna y externa. "E1 lenguaje, escribe Cassirer, no entra en un mundo de percepciones objetivas acabadas, para añadir solamente a objetos individuales dados y claranente delimitados los unos por relación a los otros, "nomires'e, qué serian signos puramente exteriores y arbitrarios, sino que es él mismo un mediador en la formación de los objetos; es, en un sentido, el mediador por excelencia, el instrumento más importante y preciso para la conquista y para la construcción de un verdadero mundo de objetos". (I3)

Esta tesis se ilustra por las observaciones de la psicología infantil, relativas a la formación del lenguaje, de las cuales aparece que el nombre actúa, en el espíritu del niño no

(13) Cassirer: en la obra antes citada: Le Langage et la Construction dn Nonde des Objets. Tradueción francesa, página 23. 
como un mero signo adherido exteriormente a las cosas sino como un factor decisivo en la fijación y consolidación de los objetos. Con lo cual, superando la infinita heterogeneidad de las fenómenos, permite llegar a una nueva sinopsis intelectual de lo múltiple.

/El lenguaje actúa así mismo como un factor importantísimo en la formación del mundo emocional y en la organización del mundo de la voluntad/El lenguaje con su orientación hacia la "reflexión" contiene en cierto sentido y domina la fuerza primitiva de la emoción. "La organización vocal y verbal de la emoción impicle su explosión prematura y puramente motriz y el abandono sin límites y sin resistencia a su impulsión". (I4) Verdad que conocieron muy bien los moralistas griegos cuando predicaron la subordinación de las pasiones a la ley y a las órdenes del Logos, cuyo sentido íntimo y profundo se relaciona de modo esencial con el lenguaje. De este modo el lenguaje nos abre la vía a la dominación del mundo interior como lo había hecho en el mundo exterior mediante la fornación ded los objetos. El lenguaje constituye la "perspectiva"u interna \& externa ,en que podemos ser dueños de nosotros mismos y de las cosas. "A la tendencia, al apetito, a la pasión que van directamente a las cosas el lenguaje opone siempre otra dirección, afectada de un signo contrario. En él coexisten siempre atracción y repulsión, que permanecen en una especie de equilibrio ideal. Puesto que a la necesidad de atraer inmediatamente las cosas a sí y de incorporaralas simplemente a la esfera del yo se opone aquí otra necesiđad, la de alejarlas del yo, de ponerlas fuera de él a fin de volverlas "representables" y de

(14) Obra citada, página 30. 
convertirlas en objetos, por el acto mismo que las pone fuera de sí. La fuerza de atracción está balanceada por la fuerza de abstracción"*. ( I5) Conjunción de dos procesos que hace posible la apropiación intelectual del mundo en la manera propia del lenguaje.

A1 lado del mundo de los objetos y de sus correspondientes relaciones con el sujeto, existe el mundo de la relación entre el yo y el tú, el mundo social, a cuya formación contribuye igualmente el lenguaje. Gracias al lenguaje se constituye la comunidad humana propiamente dicha en que lo individual, por instransferible e irreductible que sea, sólo se afirma gracias a la comunidad, a la universalidad de las relaciones sociales. $Y$ ese sentimiento de una individualidad indivisible y de una unidad social esencial lo funda el lenguaje, que según el claro pensamiento de Humboldt, enlaza al mismo tiempo que aisla y que encierra en la envoltura de la expresión más individual, la posibilidad de una comprensión universal. El lenguaje contribuye a la formación del sentimiento de la norma y al de la universalidad deí senticlo que equilibra el egocentrismo del lenguaje como mera expresión de si. De otto lado, haciendo posible la formación de preguntas que, en sí mismas implican la posibilidad de una respuesta, el lenguaje al propio tiempo que define y extiende el ámbitc de las adquisiciones intelectuales promueve la formación de la conciencia social en el dominio de la vida espiritual. Lo cual explica el sentimiento de extrañeza que llevó a los antiguos a considerar a los extranjeros como bárbaros, principalmente porque ignoraban el idioma de la comunidad griega o latina. Sentimiento que se expre-

(15) Ibidem, página 32-33. 
sa por boca de Ovidio cuando decía en su Tristia ex Ponto: "Barbarus hic ego sum quia non intelligor ulli". (I6)

La importancia del lenguaje en la formación del mundo de la pura imaginación (juegos de ilusión, fábula, humanización cósmica) no es menos notable. Para darse cuenta de ello, piénsese en que existe tanto en el niño como en el hombre primitivo una "concrescencia" inicial entre la imagen y la cosa, de la realidad y la apariencia, concrescencia en que el lenguaje y la actividad mítica desempeñan un papel solidario y verdaderamente inseparable. "A este respecto dice Cassirer, se puede aventurar esta paradoja: el niño no habla a las cosas porque las mira como animadas, sino al contrario, las mira como animadas porque habla con ellas". ( I7) El lenguaje y la animación universal son así dos funciones primitivamente unidas, y cuya posterior separación, hace que el universo, las cosas, los objetos caigan a la categoría de la pura materia muda-y en consecuencia inánime.

En el juego infantil puede observarse con singular relieve esta unión, estâ reciprocidad entre el lenguaje y la actividad de animación. Hablar en el niño es transferir a los objetos su propia animación interior, y constituye un elemento fundamental del juego, la fabulación es inseparable del juego infantil. La palabra es sugerida por la imagen, y la imagen por la palabra de tal modo que ambas viven, obran, existen la una para la otra. Por lo cual puede concluirse que el lenguaje es un medio específico de humanización, de antropogonía.

Finalmente en la poesía alcanza el lengtraje el apogeo de su poder constructivo y expresivo. En la poesía el lenguaje

(16) Ibidem, página 36.

(17) Ibidem, página 39. 
supera ese como eterno anatema que parece condenarlo a oscurecer aquello mismo que el lenguaje muestra, a tejer un velo de Maya entre los hombres y la realidad, en la expresión de la poesía, la palabra parece superar las críticas que de todo tiempo se han levantado contra el lenguaje acusándolo de oscurecer, deformar y desfigurar las cosas que él nos muestra y que acaso podrían ser condensadas en los versos de Schiller:

Warum kann der lebendige Geist dem Geist nicht erscheinen? Spricht die Seele, so spricht, ach! schon die Seele nicht mehr (18).

En la poesia, en efecto, se efectúa la más alta sintesis: lo más individual adquiere trascendencia universal y lo más universal se configura en la apariencia más irreductible y única. La creación poética es única, nueva, y sin embargo restena como si nos descubriese algo ignorado pero que sólo esperaba ser llamado por la palabra a la luz para surgir. Con lo cual la palabra poética no encubre sino descubre, y en su eterna novedad nos da la verdadera eternidad, intimidad, profundidar delavida.CFlla no brota como un simple resultado sino que en sí misma irradia, y por ella cobra nuevo y más viviente sentido el sentimiento del poeta.

Como se ve por las indicaciones que preceden el lenguaje no es únicamente una actividad demiúrgica que ordena y delimita una materia dada, ni tampoco una mera actividad de revelación de un sentido preexistente. El lenguaje aparece como creador de sentido, como una actividad que nó sólo extrae a la luz el contenido del alma, sino que al presentarlo lo transfigura y le confiere una nueva virtualidad

(18 Ibidem, página 41. 
de significación y de eficacia espiritual. El alma pronuncia la palabra en que se expresa, pero la palabra una vez pronunciada vuelve al alma con un nuevo y maravilloso coeficiente cle sentido y de vida. Por lo cual sin duda decía el viejo Heráclito (fragmento II5): "El alma obedece a la palabra, de la cual ella misma se alimenta".

Reuniendo ahora los hilos de nuestra disertación, creemos poder ordenar en la forma siguiente las conclusiones que derivan de una meditación sobre el lenguaje considerado como un fenómeno representativo y simbólico de la actividad universal de aparición.

I. Así como en el fondo del pensamiento y del alma hay un sentido, un algo que preexiste y domina, impregna y se manifiesta en la multiplicidad de las palabras, así en el fondo, en el principio de la realidad, existe un algo, o mejor, una unidad que se despliega, sin perderse, en la multiplicidad de las apariencias, iEl èsfuerzo especulativo del hombre consiste en encontrarj por la uvía de la inteligencia esa unidad, elevăndose por encima de la diversidad. El anhelo místico aspira a anegar la propia esencia personal en la fuente sin nombre de donde todo mana, y por ello siguie la vía de la negación y de la eminencia que recomendaba el viejo e inmortal Plotino. La poesía vive el principio y su difusión en las formas sensibles; es, como el alma, la gran intermediaria entre la invisible universalidad de lo inteligible y de lo uno y de la visible particularidad de los seres en que ellos se manifiestan y lucen.

2. Ese sentido de la existencia, ese sentido unitario, sale de sí, y sin perder su esencia, sin dejar de ser lo que es-in- 
divisible y uno-se manifiesta en la infinita variedad de las imágenes del alma y de las formas de la naturaleza. El mundo es así-ya se le considere en la armonía de su totalidad, ya en la rítmica y melódica sucesión de sus cambios, ya en la articulación de sus apariencias-un lenguaje. Los viejos cosmólogos hablahan de la "sintaxis cósmica" y los fílósofos del "idealismo alemán, principalmente Novalis, consideraban la creación como un poema, cuyo sentido era el último sentido metafísico de la realidad. Según ellos la creación era un "tropo del espíritu".

3. Del mismo modo que el lenguaje existe para que alguien lo entienda, el aparecer se da para que alguien lo cantemple y comprenda. La palabra y su significado se reflejan en el oído y en la mente El infinito mundo del aparccer se refleja en el espejo del alma. Así el reflejarse es como el objeto intencional del aparecer. $\mathrm{Y}$ así como el manifestarse sigue al ser, el reflejarse sigue al aparecer, y de este modo: Ser, aparecer y reflejo especular del aparecer se dan como las supremas categorías metafísicas.

Todo ser sale de si y tiende a ser contemplado. Y así aparece clara en'su misterio esta sentencia de Plotino: "Todo ser es contemplación, todo deriva de la contemplación". Como si en el simple existir, como si en la mera posición del ser hubiese ya algo que desprendiéndose de él lo restituyese en imagen, en visión, en palabra que no solamente se pronuncia sino que también y principalmene se oye.

4. Hemos distinguido dos grandes direcciones, dos grandes horizontes en la actividad del lenguaje: la que 1lamamos función demiúrgica y que consiste en que el lenguaje-como la mente de la cual es al propio tiempo instrumento $y$ factor-se ejercita ordenando el vario conjunto de los 
objetos, definiéndolos y delimitándolos. Es una función abstractiva que expresa, designa las especies y extrac las esencias. Y que actúa con cierta exterioridad sobre los contenidos que designa y fija. Y la que llamamos operación hipostática en que el lenguaje es propiamente hablando, expresión. Es el salir de sí del ser en sí. Es el lenguaje sintético de la afectividad y de la poesía.

Entre estas dos funciones o direcciones del lenguaje inherentes a las operaciones naturales de la mente se da una cierta oposición. La una es generalizadora, abstractiva, esquemática. Corresponde a la función lógica. La otra-hasta en sus simbolizaciones más universales y signifcativas-es concreta, imaginativa, imaginífera. Es la función expresiva, poética. La una se aplica a los objetos, los delimita y ordena, la otra supone una emanación del interior, emanación que como un fhuído se difunde en el espacio físico y anímico. Hay empero, entre ellas, una intima relación, y el secreto de esa relación es sin duda, el gran secreto de la estructura más honda de lo real. E1 lehiguajeces una énanación-del alma, del espíritu, del ser runiversal-pere el objeto intencional del lenguraje está más allá de él, como si la palabra, el verbo absoluto, necesitase un algo distinto de él, que al mismo tiempo y por el hecho de nombrar, pone, para siempre, con subsistencia metafísica, fuera de sí.

$55^{\circ}$ El lenguaje prolonga el movimiento interno y creador que le da nacimiento, y por ello nos presenta el ejemplo de un devenir cuyas fases están ligadas, sin duda, por una relación de filiación con la primitiva unidad de sentido pero que al mismo tiempo la enriquecen y transfiguran al revelarla. Con lo cual la poesía se da no como una mera imitación del modelo ideal sino como la expresión de una energía capaz de 
suscitar nuevas apariencias, formas inéditas que al par que manifiestan renuevan el sentido y lo transponen a planos cada vez más lejanos y extensos.

$6 .^{2}$ El lenguaje como toda forma del aparecer, al propio tiempo que viene del ser tiene una proyección de retorno hacia el ser que es el sentido, y que a la vez que se da en el lenguaje, lo trasciende. El hablar, es poner en acto estas dos categorías ontológicas inseparables y distintas: el aparecer y el ser. Algo se revela en la sonoridad de la palabra, algo que no es la palabra sino su objeto significado. Entender es deshacer la mera aparencialidad de la palabra para descubrir el sentido supraverbal, ontológico del verbo. $Y$ así el hablar y el entender nos entregan en resumen toda la polaridad metafísica de lo real.

Pero hay más, como bien se comprende, en todo lenguaje se da una proyección hacia la cosa en sí. Hablar y entender es sentir o intuir que más allá de la palabra existe algo que la palabra, sin duda, expresa, manifiesta, pero que no se agota en la mera soriouidad de la expresión. Ese algo aunque no es posible separarlo de hecho comos bura intuición sin expresión, es una cosa en sí. Y de este modo, el lenguaje nos ilustra no sólo sobre la calidad que díriamos categorial de la cosa en sí, no sólo sobre la inevitabilidad de su presencia en todo fenómeno de expresión, sino sobre la realidad de su existencia que, de un modo o de otro, transparece, en todo fenómeno de visión o audición significativa.

Mariano Iberico, 